\title{
AN ENHANCED G-PON FAULT MONITORING TECHNIQUE USING OPTICAL SENSOR
}

\author{
Auwalu Usman* \\ Lightwave Communication Research Group, Faculty of Engineering \\ Universiti Teknologi Malaysia \\ Malaysia \\ Nadiatulhuda Zulkifli \\ Lightwave Communication Research Group, Faculty of Engineering \\ Universiti Teknologi Malaysia \\ Malaysia \\ Mohd Rashidi Bin Salim \\ Lightwave Communication Research Group, Faculty of Engineering \\ Universiti Teknologi Malaysia \\ Malaysia \\ Kharina Khairi \\ Fixed Infra Media Lab \\ TM Research \& Development Sdn Bhd, Selangor \\ Malaysia
}

*Corrosponding author's Email: uauwalu2@graduate.utm.my

Peer-review under responsibility of $3^{\text {rd }}$ Asia International Multidisciplanry Conference 2019 editorial board (http://www.utm.my/asia/our-team/)

(C) 2019 Published by Readers Insight Publisher, lat 306 Savoy Residencia, Block 3 F11/1,44000 Islamabad. Pakistan,

info@ readersinsight.net

This is an open access article under the CC BY-NC-ND license (http://creativecommons.org/licenses/by-nc-nd/4.0/). 


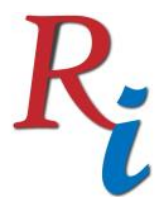

\section{Science Proceedings Series (SPS) \\ www.readersinsight.net/SPS}

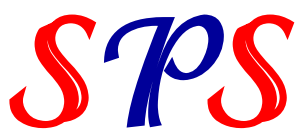

\section{R E S E A R C H H I G H L I G H T S}

In this study a technique for a centralized fault monitoring and detection in Gigabit-capable Passive Optical Network (G-PON) using fiber Bragg grating (FBG) sensor is proposed. The technique detects fault once it occurs at the vulnerable locations in the fiber optic distribution link by the proposed FBG devices. Monitoring signal in the C-band is reflected by a uniform FBG with different Bragg wavelengths and reflectivities. The FBGs serve as branch identifiers in the network. The reflected signal from the FBGs is analyzed at the Optical Line Terminal (OLT) in the Central Office (CO) by an Optical Spectrum Analyzer (OSA), to identify the branch with rupture in the network. The simulated result obtained shows that the system can monitor, and detect a fault in the physical layer of the optical distribution network with negligible effects on data signal transmission.

\section{G R A P H I C A L A B S TR A C T}

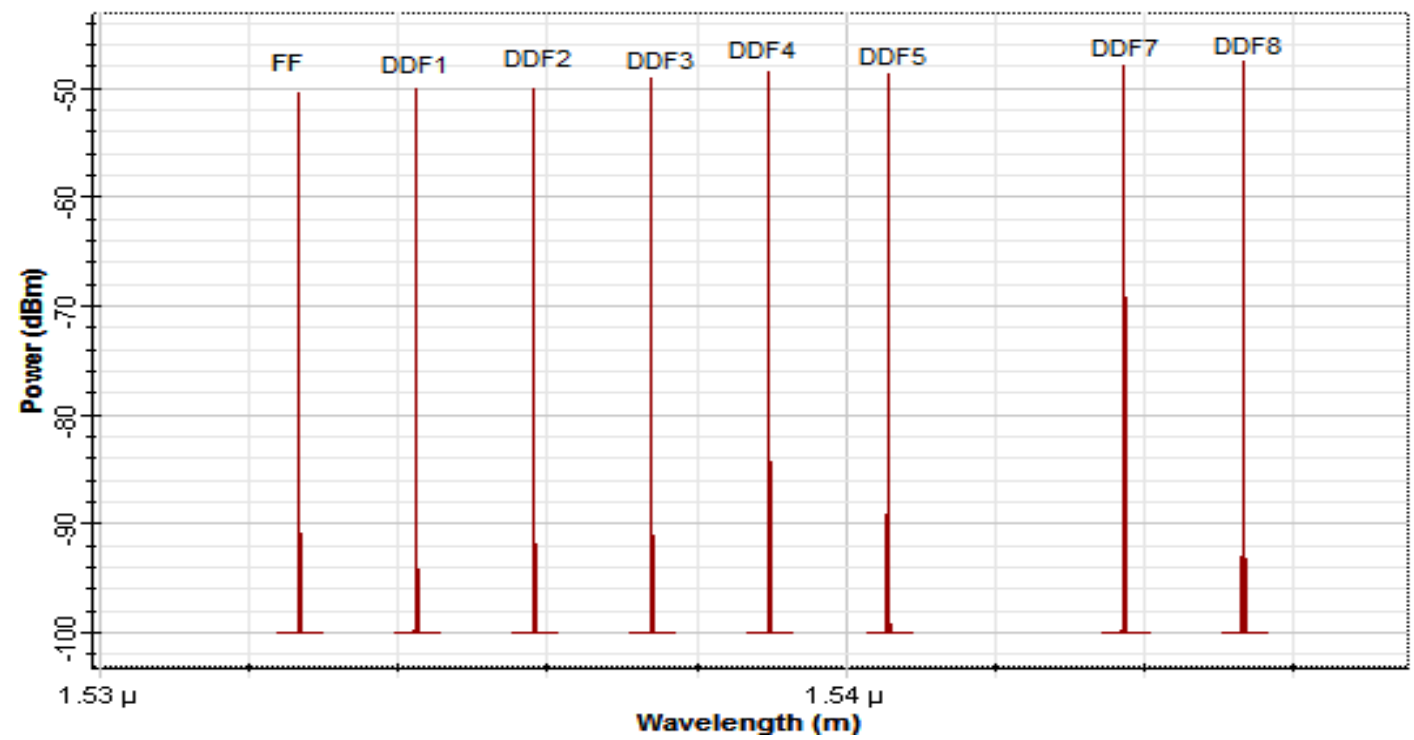

Fig. 1. Reflection spectra of the OSA indicating fiber break at the DDF6 in the DF links

\section{RESEARCH OBJECTIVES}

Failure detection in the physical layer of PON is an invaluable task for the network service providers to ensure the delivery of effective and efficient broadband services to the subscribers. It is difficult to detect a failure in the PON physical layer when the OLT/ONU management control interface cannot identify the failure branch in the fiber link (1). Hence, many telecom operators look for the centralized PON monitoring system that can easily identify and detect a fault in the fiber link. Several PON monitoring techniques have been proposed to monitor the PON physical layer $(2,3)$. However, most of these solutions are either too complex or expensive for actual deployment. This study intends to propose a simple and low cost method for the characterization of fault in a PON physical layer.

\section{MATERIALS AND METHODS}

In the proposed model shown in Figure 2, the modulated data signal for downstream and upstream are transmitted over $1490 \mathrm{~nm}$ and $1300 \mathrm{~nm}$ wavelength respectively. A Continuous Wave $(\mathrm{CW})$ laser source is used to generate the monitoring signal at a frequency of $194 \mathrm{THz}$ 


\section{$R_{i}$}

\section{Science Proceedings Series (SPS) \\ www.readersinsight.net/SPS}

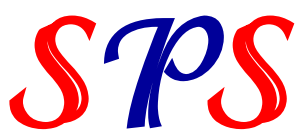

with a frequency spacing of $200 \mathrm{GHz}$, a pump laser source of $100 \mathrm{mw}$ at a frequency of 980 $\mathrm{nm}$ is coupled with the monitoring signal through a pump coupler co-propagate (OCP) with 0 $\mathrm{dB}$ attenuation. Initially, the monitoring power is $0 \mathrm{dBm}$ an EDFA with a pump laser is used to amplify the signal to $21 \mathrm{dBm}$. The two signals, data, and monitoring are coupled through a bi-directional optical circulator (OC), and transmitted over the feeder fiber (FF), at a distance of $20 \mathrm{~km}$. The FBGs are located at the distribution and drop fiber (DDF) section, between the PSC and the ONU. A dedicated FBG is placed before the PSC to monitor the health status of the fiber link between the OLT and the remote node. These FBGs have varying center wavelengths between $1530 \mathrm{~nm}$ to $1540 \mathrm{~nm}$ determine by equation 1, with a reflectivity of > 90 $\%$ obtained as in equation 2, and a bandwidth of $125 \mathrm{GHz}$.

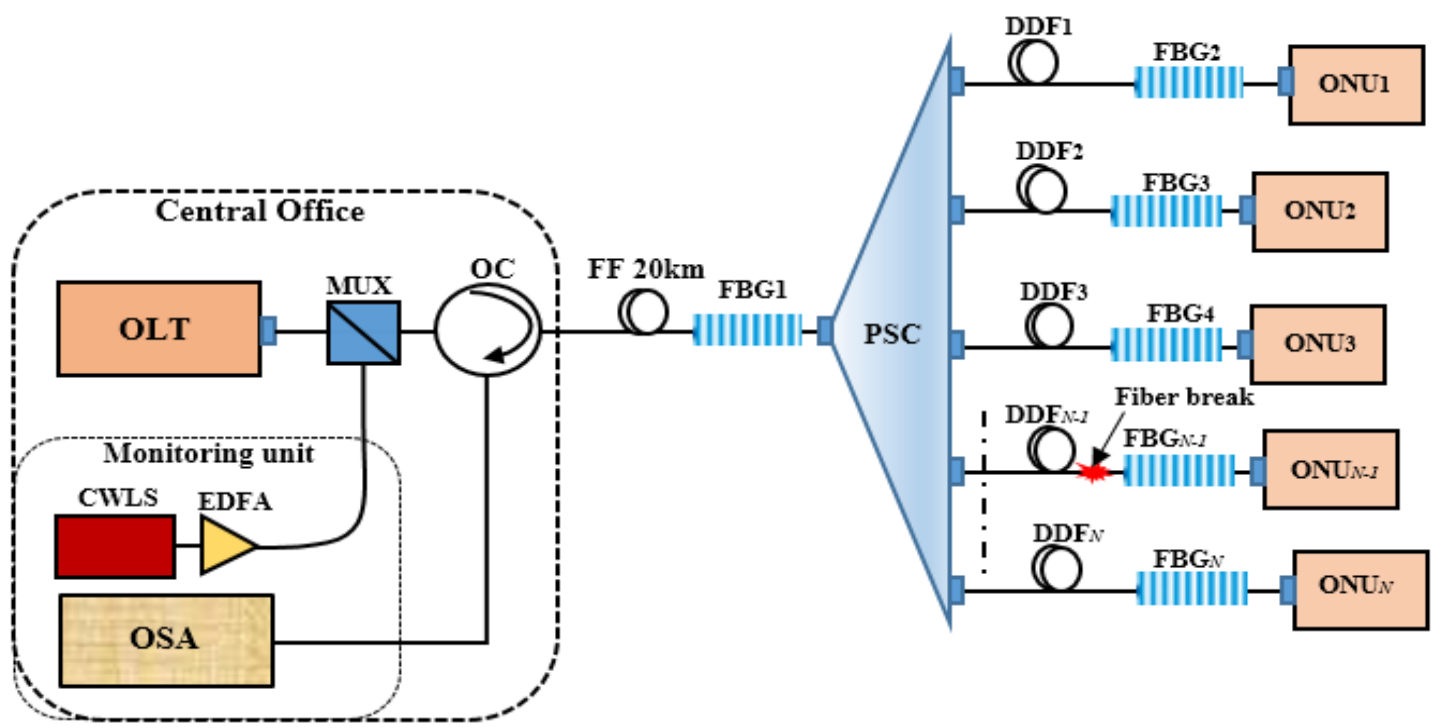

Fig. 2. FBG based centralized G-PON monitoring of fault in FTTx network

The Bragg wavelength $\lambda_{B}$ is given as

$\lambda_{B}=2 n_{e f f} \Lambda$

Where $n_{\text {eff }}$ is the effective refractive index of the fiber core and $\Lambda$ is the grating period. The maximum reflectivity of the FBG can be obtain using equation 2

$R=\left(1-10^{-\frac{d}{10}}\right) \times 100$

Where $R$ is the FBG reflectivity and $d$ is the power dip of the spectrum $(4,5)$.

\section{RESULTS}

A uniform FBG sensor reflects the signal at different power levels. The FBGs operate at different Bragg wavelength that enables the signal from different sources to be reflected. The measured monitoring signal spectra are analyzed using the optical spectrum analyzer (OSA) with an optical resolution of $0.01 \mathrm{~nm}$. The signals are of different power level due to a nonflattening gain of the EDFA. The maximum gain of $15.5 \mathrm{~dB}$ is achieved at an OSNR of $51 \mathrm{~dB}$ at the monitoring unit. Noise measurement of the laser source at different wavelength shows a minimum of $-100 \mathrm{dBm}$ and a maximum of $-66 \mathrm{dBm}$.

The minimum reflected signal received is $\sim-58 \mathrm{dBm}$, power degradation and missing reflection spectra in the network indicate fiber fault in the particular network branch. In normal operation of the G-PON without any fault in the optical link all, the reflections from the FBGs are present at a considerable power level of about $-44 \mathrm{dBm}$ to approximately $-58 \mathrm{dBm}$, but under the faulty 


\section{$R_{i}$}

\section{Science Proceedings Series (SPS) \\ www.readersinsight.net/SPS}

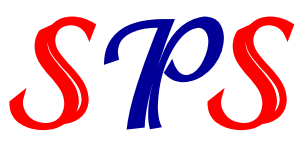

condition the signal power significantly drops for various DDF impairments. The reflection spectrum of Figure 7 indicates fiber break with total missing reflection at the $\mathrm{DDF}_{6}$ link in the network. The attenuation at the $20 \mathrm{~km}$ FF is $0.2 \mathrm{~dB} / \mathrm{km}$ bi-directional, the insertion loss for both the OC and PSC are $1 \mathrm{~dB}$ and $0.6 \mathrm{~dB}$ bi-directional respectively, and PSC insertion loss is $1.5 \mathrm{~dB}$. Splice loss is $0.1 \mathrm{db} / \mathrm{km}$ and connector loss at the transmitter and receiver is $1 \mathrm{~dB}$ each.

\section{FINDINGS}

A simple method to monitor G-PON fault is proposed, the technique employs FBGs as a device to detect a fault in the fiber branches. The monitoring signal is generated at the OLT in the CO using an unmodulated $\mathrm{CW}$ laser source. The uniform FBGs located in the fiber branches reflects the monitoring signal; the reflected signal is analyzed with OSA to determine the fiber branch with fault. Significant drop of the reflected power received can recognize the status of the faulty fiber unit. Results obtained shows the capability for the scheme to monitor the network at a distance of $20 \mathrm{~km}$ with minimum optical reflected power received $-58 \mathrm{dBm}$, at 51 dB OSNR with negligible effect on the data signal transmission.

\section{ACKNOWLEDGEMENT}

The authors acknowledge the Ministry of Higher Education (MOHE) Malaysia and Research Management Centre, Universiti Teknologi Malaysia for the financial support through the Transdisciplinary Research Grant (TDR) GUP T1, vote number 05 G60 and Fundamental Research Grant Scheme, FRGS vote number 5F086.

\section{REFERENCES}

1. Zhou X, Zhang F, Sun X. Centralized PON Monitoring Scheme Based on Optical Coding. IEEE Photonics Technology Letters. 2013;25(9):795-7.

2. Esmail MA, Fathallah H. Physical Layer Monitoring Techniques for TDM-Passive Optical Networks: A Survey. IEEE Communications Surveys \& Tutorials. 2013;15(2):943-58.

3. Zhang X, Sun X. Optical pulse width modulation based TDM-PON monitoring with asymmetric loop in ONUs. Sci Rep. 2018;8(1):4472.

4. Daud S, Ali J. Fibre Bragg Grating and No-Core Fibre Sensors: Springer International Publishing; 2018.

5. Grattan LS, Meggitt BT. Optical Fiber Sensor Technology: Advanced Applications - Bragg Gratings and Distributed Sensors: Springer US; 2013. 